\title{
Efficacy of oral iron therapy in improving the developmental outcome of pre-school children with non-anaemic iron deficiency: a systematic review
}

\author{
Kawsari Abdullah ${ }^{1,2}$, Tetyana Kendzerska ${ }^{2}$, Prakesh Shah $^{2,3}$, Elizabeth Uleryk ${ }^{4}$ and \\ Patricia C Parkin $1,2,5, *$ \\ 'Division of Pediatric Medicine and the Pediatric Outcomes Research Team (PORT), Hospital for Sick Children, \\ 555 University Avenue, Toronto, Ontario, Canada, M5G 1X8: ${ }^{2}$ Departments of Pediatrics, and Health Policy, \\ Management and Evaluation, Faculty of Medicine, University of Toronto, Toronto, Canada: ${ }^{3}$ Department of \\ Pediatrics, Mount Sinai Hospital, University of Toronto, Toronto, Canada: ${ }^{4}$ Hospital Library and Archives, \\ Hospital for Sick Children, Toronto, Canada: ${ }^{5}$ Child Health Evaluation Program, Hospital for Sick Children \\ Research Institute, Toronto, Canada
}

Submitted 4 September 2011: Final revision received 5 June 2012: Accepted 29 June 2012: First published online 16 August 2012

\begin{abstract}
Objective: To systematically review the efficacy and safety of oral Fe therapy in pre-school children (1-5 years) with non-anaemic Fe deficiency, determined by children's developmental and haematological status and the incidence of reported side-effects.

Design: A random-effects model was used to show mean differences with $95 \%$ confidence intervals of developmental and haematological scores between Fe-treated and non-treated groups.

Setting: MEDLINE, EMBASE, Cochrane library and bibliographies of identified articles were searched up to September 2011. Randomized and observational studies were assessed by two reviewers independently. Quality of the trials was assessed on the basis of concealment of allocation, method of randomization, masking of outcome assessment and completeness of follow-up.

Subjects: From the titles of 743 articles, full text review was completed on forty-six and two randomized trials of acceptable quality met the inclusion criteria. The two trials included a total of sixty-nine children.

Results: One study showed a statistically significant difference in the post-treatment Mental Developmental Index score among children who received oral Fe therapy $v$. no therapy (mean difference $=6 \cdot 3,95 \%$ CI $1 \cdot 5,11 \cdot 0, P$ value not provided). Both studies showed significant improvement in serum ferritin level $(\mu \mathrm{g} / \mathrm{l}$ : mean difference $=51 \cdot 1,95 \%$ CI 33.6, 68.6, $P<0 \cdot 01$ and mean difference $=17 \cdot 1,95 \%$ CI $7 \cdot 5$, 26.6, $P$ value not provided, respectively) in children who received Fe therapy. Conclusions: Evidence is insufficient to recommend oral Fe therapy to children with non-anaemic Fe deficiency. There is urgent need of conducting adequately powered, randomized trials examining the efficacy of oral Fe therapy in pre-school children with non-anaemic Fe deficiency.
\end{abstract}

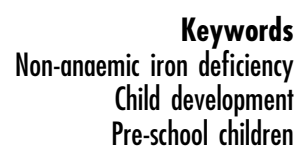

Iron deficiency (ID) is the most common and widespread nutritional disorder in the world ${ }^{(1)}$. ID represents a spectrum ranging from non-anaemic iron deficiency (NAID: normal $\mathrm{Hb}$, low $\mathrm{Fe}$ status) to iron deficiency with anaemia (IDA: low $\mathrm{Hb}$, low Fe status). Because $\mathrm{Fe}$ is involved in many central nervous system processes, its deficiency may adversely affect the cognitive performance and motor development in children ${ }^{(2-4)}$.
Summarized in two systematic reviews, numerous studies have established a relationship between IDA and poor cognitive and motor development in infants and children ${ }^{(5,6)}$. However, there is conflicting evidence as to whether this delay can be reversed following treatment with oral Fe. Most randomized trials have shown that children treated with the recommended dose and duration of Fe have corrected anaemia but biochemical 
evidence of ID as well as poor cognitive and motor development persist ${ }^{(7-9)}$. These findings suggest that ID, when it reaches its most severe stage, may have irreversible effects.

Mild to moderate ID has also been associated with adverse developmental consequences. Observational studies suggest that, compared with children who are Fe sufficient, children with NAID tend to have lower developmental scores, verbal competency, comprehension and intelligence quotient ${ }^{(8,10,11)}$. However, studies focusing on the efficacy of Fe therapy in children with IDA and also including children with NAID and Fe sufficiency as comparison groups did not show developmental difference between the latter two groups ${ }^{(7)}$. Thus, the severity of ID that may impact the development of children remains unknown. Current WHO and American Academy of Pediatrics guidelines do not recommend screening for NAID ${ }^{(2,12)}$. Therefore, children with this condition are less likely to be identified and treated. This further adds to the insufficient evidence base relating NAID as a cause of poor development in children and the efficacy of Fe therapy in this population. Furthermore, it is possible that the relationship between ID and development is confounded by other factors like low socio-economic factors, poor maternal education, low birth weight, early weaning and parasitic infection ${ }^{(13-16)}$.

Oral Fe is the treatment of choice for IDA because of its effectiveness, safety and cost-effectiveness ${ }^{(17,18)}$. When taking Fe preparations orally, side-effects occur occasionally in the form of staining of teeth, vomiting, heartburn, darkening of stools, constipation or loose stools $^{(19,20)}$. Rates of non-compliance attributed to sideeffects range from $0 \%$ to $6 \%{ }^{(21)}$.

The current controversy regarding ID in children relates to the degree of ID that impairs child development and the efficacy of Fe therapy in correcting developmental deficits $^{(22)}$. The overall aim of the present evidence synthesis was to determine whether there is enough evidence to suggest that NAID is causally associated with poor development in children and whether oral Fe therapy is effective in improving development in pre-school children with NAID. Considering the irreversible developmental impact of IDA, we hope that this systematic review will focus attention on NAID, the early stage of ID, in order to build an evidence base for screening and treatment of NAID to prevent progression to IDA.

\section{Objectives}

The primary objective of the current review was to evaluate the efficacy of oral Fe therapy in children of pre-school age (1-5 years) with NAID, defined as serum ferritin $<12 \mu \mathrm{g} / 1$ and $\mathrm{Hb}>110 \mathrm{~g} / \mathrm{l}$, in improving developmental outcomes. The secondary objectives were to evaluate the efficacy of oral Fe therapy in terms of haematological outcomes and incidence of side-effects of Fe therapy in children of pre-school age (1-5 years) with NAID.

\section{Methods}

\section{Criteria for considering studies for review}

Types of studies

Randomized or quasi-randomized controlled trials and observational studies with prospective longitudinal design were considered for the current review. Separate metaanalysis for observational studies and randomized controlled trials were planned to avoid methodological heterogeneity.

\section{Types of participants}

The participants were Fe deficient (serum ferritin $<12 \mu \mathrm{g} / \mathrm{l}$ ) but non-anaemic $(\mathrm{Hb}>110 \mathrm{~g} / \mathrm{l})$ children who were otherwise healthy and aged $1-5$ years. Studies on children with developmental disorders, chronic disease, congenital or genetic disorder and ID were excluded.

\section{Types of interventions}

The dose and duration of Fe therapy have been established for IDA but not for NAID. According to guidelines for the prevention of IDA and the opinion of experts, it was decided to select studies with a minimal dose of $2 \mathrm{mg}$ elemental $\mathrm{Fe} / \mathrm{kg}$ body weight per d once daily, administered for a minimum duration of 3 months ${ }^{(2,23)}$. The treatment group included children who received oral Fe therapy ( $\geq 2 \mathrm{mg}$ elemental $\mathrm{Fe} / \mathrm{kg}$ body weight per $\mathrm{d}$ administered for $\geq 3$ months) with or without other interventions aimed at improving Fe level (such as dietary counselling, vitamin C, folic acid). The control group included children receiving placebo or no treatment.

\section{Types of outcome measures}

Primary outcome. The primary outcome for the current review was the change or the end-of-study scores of children's development, measured using any standardized scale that can be converted to standard scores expressed by mean and standard deviation. Bayley's Scale of Infant Development (BSID) is one such scale which has a population mean of 100 and an SD of $15^{(24)}$.

Secondary outcomes. Secondary outcomes included the change or the end-of-study levels of $\mathrm{Hb}$ and serum ferritin. Safety outcomes included the rate of any reported side-effects of Fe treatment including vomiting, heartburn, constipation, loose stools, staining of teeth and darkening of stools.

\section{Search methods for identification of studies}

A comprehensive search strategy was performed to identify all relevant studies, including searching the electronic literature and hand searching. We searched the following electronic databases and updated results as of 13 January 2011: MEDLINE (1950 to the present), EMBASE (1980-2011 Week 1) and the Cochrane Controlled Trials Register (CCTR; Cochrane Library issue 4, 2010). We scanned reference lists of identified trials and important 
review articles for published studies which may have been missed by the literature search. We included only published data in English language. However, we planned to contact key authors of those articles where we expected to find data not published but relevant to our review.

\section{Search terms}

Under the supervision of an expert librarian (E.U.), the following key search terms were used: 'anemia/ hypochromic anemia', 'iron/blood', 'iron-deficiency' and 'ferritin' combined with concepts of child development. Appropriate truncations and possible misspellings were included. Where appropriate, a trials search filter was applied. The described search strategy (detailed search strategy shown in the Appendix) was used for MEDLINE. For use with EMBASE and the Cochrane Library this strategy was adapted slightly.

\section{Data collection and analysis}

Selection of studies

Titles and abstracts of studies identified on searches of electronic databases were read to determine whether they might meet the inclusion criteria. Full copies of those possibly meeting these criteria were assessed by two independent reviewers (K.A., T.K.). Studies that met the inclusion criteria were again reviewed by the same reviewers for quality assessment. Differences of opinion about inclusion of studies and quality assessment of studies were resolved by discussion. Arbitration by a third reviewer (P.C.P.) was kept open.

\section{Assessment of risk of bias in included studies} For randomized controlled trials, the two reviewers (K.A., T.K.) independently assessed the methodological quality of the studies using a predefined checklist, as suggested for the Cochrane Database of Systematic Reviews $^{(25)}$. We performed an overall assessment of risk of bias, based on responses from criteria used to assess the quality of the studies. Studies that reached A or B score were intended to be included in the meta-analysis. For studies with longitudinal designs we intended to score the quality of the studies using the Newcastle-Ottawa Scale (NOS) $)^{(26)}$. We planned to include studies that had at least one star in each category of the scale. Assessment was intended to be carried out independently by two reviewers.

\section{Data extraction and synthesis}

We planned to use the RevMan software version $5 \cdot 0$ to generate meta-analyses and show summarized effect size if appropriate data were available. Data regarding the stated outcomes of the review (standardized mean difference (SMD) or mean difference (MD) with 95\% CI for continuous outcomes and relative risk (RR) with 95\% CI for binary outcomes) were extracted and entered into the RevMan software. The original data were not modified but for the purpose of data synthesis for meta-analysis, calculations were required from available data. Pooled results were to be presented as forest plots. Statistical heterogeneity was assessed using the Cochran $Q$ test and by calculating $I^{2}$ values. We expected methodological, clinical and statistical heterogeneity among the studies. Thus, we intended to use the random-effect model for meta-analyses. Subgroup analysis for children aged $<2$ and $\geq 2$ years was planned. The robustness of the results were intended to be checked by performing sensitivity analysis showing the influence of study quality as well as the influence of large-scale studies. In the case of duplicate publications and companion papers of a primary study, the original publication (usually the oldest version) obtained priority. We intended to assess publication bias using the funnel plot method.

\section{Results}

\section{Literature search}

Excluding duplicates, 743 articles were identified in first scan; 697 were excluded after reading the titles and abstract (Fig. 1). Full text review was completed on fortysix articles and we identified two randomized clinical trials of oral Fe treatment in which children with NAID were randomized to a treatment or control $\operatorname{group}^{(27,28)}$. For both studies, the primary objective was to study children with IDA; however, both included children with NAID as a comparison group, and these data were available for the review. No studies with observational design met the inclusion criteria. The reason for exclusion of forty-four studies is reported in Table 1.

\section{Study participants and interventions}

The baseline characteristics of the children in the two included studies and the dosage and duration of oral $\mathrm{Fe}$ treatment are reported in Table 2. Both studies used the same inclusion criteria: birth weight greater than $2500 \mathrm{~g}$; singleton; no major congenital anomalies; no jaundice treated by phototherapy; no hospital admission or supplementation with micronutrients during the 6 months before enrollment; no clinically identified neuromotor delay; no chronic illness or folic acid deficiency; no signs of abnormal haemoglobinopathy or thalessaemia; and weight, length and head circumference within \pm 2 sD of reference standard.

Akman et al. (2004, Turkey) included 108 children aged 6-30 months (average age 17 months) ${ }^{(28)}$. Of these, forty (37\%) had NAID; twenty-one received oral Fe treatment and nineteen received no treatment. Oral $\mathrm{Fe}$ was given for 3 months at a dose of $3 \mathrm{mg}$ elemental $\mathrm{Fe} / \mathrm{kg}$ body weight per $\mathrm{d}$, twice daily. The $\mathrm{Hb}$ and serum ferritin cut-offs were: IDA $(\mathrm{Hb}<11 \mathrm{~g} / \mathrm{dl}$, serum ferritin $\leq 12 \mu \mathrm{g} / \mathrm{l}$, mean corpuscular volume $<70 \mathrm{fl})$ and NAID $(\mathrm{Hb} \geq 11 \mathrm{~g} / \mathrm{dl}$, serum ferritin $\leq 12 \mu \mathrm{g} / \mathrm{l}$, mean corpuscular volume $\geq 70 \mathrm{fl}$ ). 


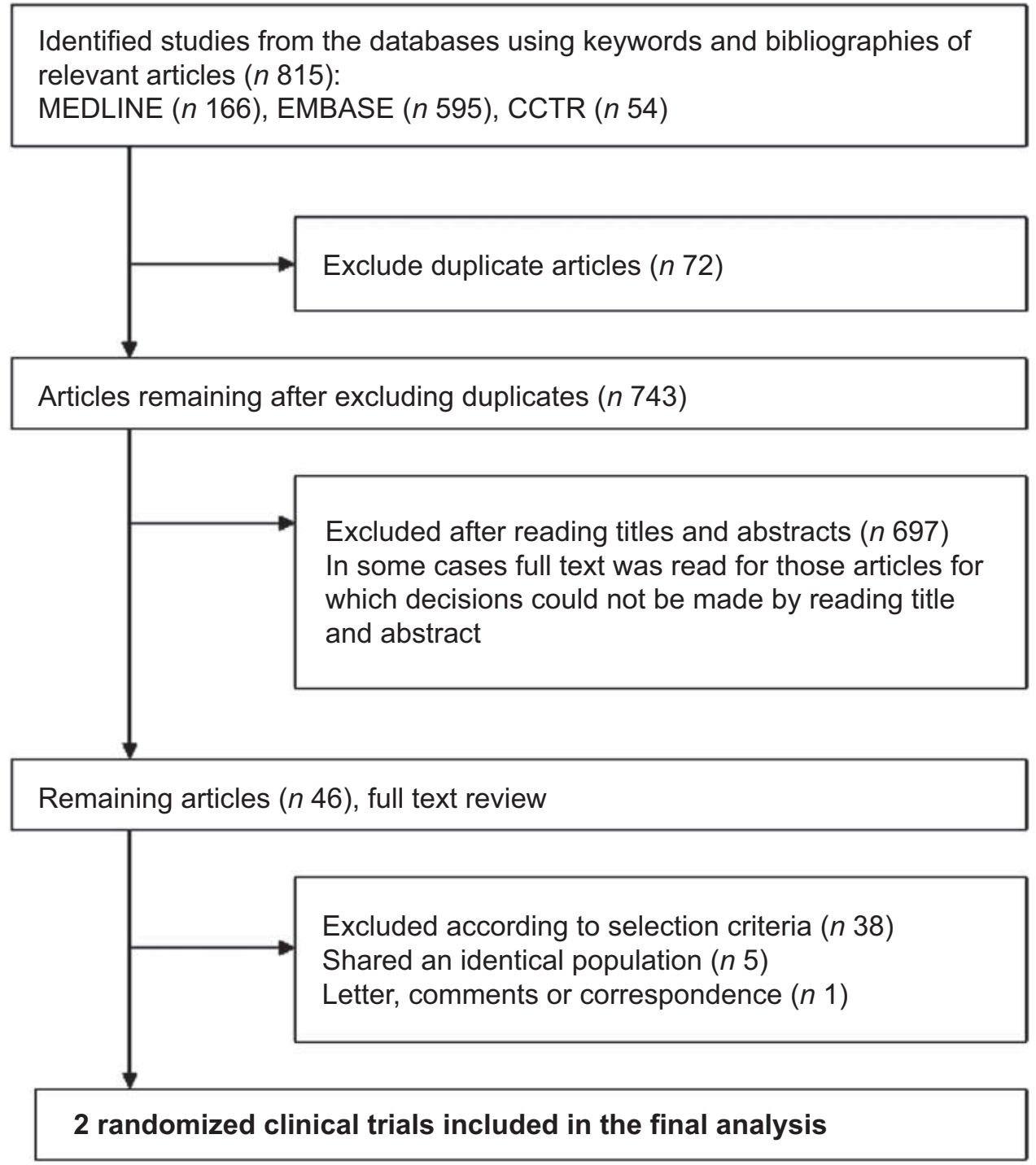

Fig. 1 Flow diagram for selection of studies in the current review

Idjradinata et al. (1993, Indonesia) included 141 children aged 12-18 months ${ }^{(27)}$. Of these, twenty-nine (21\%) had NAID; fourteen received oral Fe treatment and fifteen received no treatment. The oral Fe was given for 4 months at a dose of $3 \mathrm{mg}$ of elemental $\mathrm{Fe} / \mathrm{kg}$ body weight per $\mathrm{d}$. The $\mathrm{Hb}$ and serum ferritin cut-offs were: IDA $(\mathrm{Hb}<105 \mathrm{~g} / \mathrm{l}$, transferrin saturation $\leq 10 \%$ and serum ferritin $\leq 12 \mu \mathrm{g} / \mathrm{l}$ ) or NAID $(\mathrm{Hb} \geq 120 \mathrm{~g} / \mathrm{l}$, transferrin saturation $\leq 10 \%$ and serum ferritin $\leq 12 \mu \mathrm{g} / \mathrm{l})$. Children whose $\mathrm{Hb}$ level was between 105 and $120 \mathrm{~g} / 1$ were excluded.

\section{Metbodological quality}

The results of the assessment of the risk of bias of the two included studies are reported in Table 3. Both studies showed moderate risk of bias (B quality). Both studies provided insufficient information regarding allocation concealment. Akman et al. (2004, Turkey) was a singleblind trial; mothers were not blinded because placebo was not used. Further, although the two groups differed in a number of variables, for example sociodemographic variables, it was not clear whether the analysis was adjusted for these differences. Idjradinata et al. (1993, Indonesia) did not report on the method of laboratory analysis. Both studies reported child development using the BSID. This scale reports development using two indices, the Mental Developmental Index (MDI) and the Psychomotor Developmental Index (PDI), with the standardized score having a mean of 100 and an SD of \pm 15 .

\section{Outcomes}

Meta-analyses were not performed due to high level of heterogeneity (see 'Heterogeneity and publication bias' section) between the two studies. Considering the primary outcome, comparison of the MDI and PDI in the Fe-treated and non-treated NAID groups, Akman et al. (2004, Turkey) showed a statistically significant difference in 
Table 1 Characteristics of studies excluded from the current review

\begin{tabular}{|c|c|}
\hline No. & Author, date, country \\
\hline 1. & Aukett et al., 1986, Britain \\
\hline 2. & Ayala et al., 2008, Mexico \\
\hline 3. & Black et al., 2004, Bangladesh \\
\hline 4. & Corapci et al., 2006, Costa Rica \\
\hline 5. & Deinard et al., 1986, USA \\
\hline 6. & Engle et al., 1999, Guatemala \\
\hline 7. & Friel et al., 2003, Canada \\
\hline 8. & Gonzalez et al., 2007, Argentina \\
\hline 9. & Gunnarsson et al., 2007, Iceland \\
\hline 10. & Harahap et al., 2000, Indonesia \\
\hline 11. & Hokama et al., 2005, Japan \\
\hline 12. & Lind et al., 2004, Central Java \\
\hline 13. & Lozoff et al., 1982, Guatemala \\
\hline 14. & Lozoff et al., 1985, Guatemala \\
\hline 15. & Lozoff et al., 1987, Costa Rica \\
\hline 16. & Lozoff, 1989, Costa Rica \\
\hline 17. & Lozoff et al., 1991, Costa Rica \\
\hline 18. & Lozoff et al., 1996, Costa Rica \\
\hline 19. & Lozoff et al., 1998, Costa Rica \\
\hline 20. & Lozoff et al., 2000, Costa Rica \\
\hline 21. & Lozoff et al., 2003, Chile \\
\hline 22. & Lozoff et al., 2006, Costa Rica \\
\hline 23. & Lozoff et al., 2007, India \\
\hline 24. & $\begin{array}{l}\text { Metallinos-Katsaras et al., } \\
\text { 2004, Greece }\end{array}$ \\
\hline 25. & Olney et al., 2007, Tanzania \\
\hline
\end{tabular}

Otero et al., 2004, Mexico

Pollitt et al., 1985

28. Pollitt et al., 1986, Guatemala

29. Pollitt, 2001, Canada

30. Pollitt et al., 2002, Indonesia

31. Seshadri et al., 1982, India

32. Shafir et al., 2006, Costa Rica

33. Soemantri et al., 1985, Indonesia

34. Soewondo et al., 1989, Indonesia

35. Steinmacher et al., 2007, Germany

36. Stoltzfus et al., 2001, Zanzibar

37. Sungthong et al., 2004, Thailand

38. Walter et al., 1983

39. Walter et al., 1989, Chile

40. Walter, 1989, Chile

41. Yalcin et al., 2000, Turkey

42. Corapci et al., 2010, Costa Rica

43. Gupta et al., 2010, India

44. Lozoff et al., 2010, Chile

Reason for exclusion

Did not meet $\mathrm{Hb}$ inclusion criteria

Did not meet $\mathrm{Hb}$ inclusion criteria; did not

meet age inclusion criteria

Did not meet age inclusion criteria

Follow-up of Lozoff et al., 1987 study

Did not meet serum ferritin inclusion criteria

Did not meet intervention inclusion criteria

Did not meet NAID definition

Did not meet intervention inclusion criteria

Did not meet intervention inclusion criteria

Did not meet $\mathrm{Hb}$ inclusion criteria

Did not meet intervention inclusion criteria; did not meet NAID definition

Did not meet $\mathrm{Hb}$ and serum ferritin inclusion criteria

Did not meet NAID definition

Follow up of Lozoff et al., 1982 study

Did not include a control group of children with NAID Follow up of Lozoff et al., 1987 study

Follow-up of Lozoff et al., 1987 study

Did not include a control group of children with NAID

Follow up of Lozoff et al., 1987 study

Follow up of Lozoff et al., 1987 study

Did not meet intervention inclusion criteria

Follow up of Lozoff et al., 1987 study

Did not include NAID group

Did not include NAID group in analysis

Did not meet serum ferritin inclusion criteria; did not meet study design criteria (a cross-sectional analysis)

Did not meet age inclusion criteria

A letter to the editor

Did not include NAID group

Not an original study

Did not meet healthy child inclusion criteria; did not meet intervention inclusion criteria

Did not meet age inclusion criteria

Follow-up of Lozoff et al., 1987 study

Did not meet age inclusion criteria;

did not include NAID group

Did not include a control group of children with NAID

Did not meet healthy child inclusion criteria; did not meet age inclusion criteria

Did not meet intervention inclusion criteria; did not include NAID group

Did not meet intervention inclusion criteria; did not include NAID group

Did not meet duration and dose of intervention inclusion criteria

Did not meet duration and dose of intervention inclusion criteria

Did not meet duration and dose of intervention inclusion criteria

Did not meet age inclusion criteria

Follow-up of Lozoff et al., 1987 study

Did not include NAID group

Did not meet age inclusion criteria; did not meet intervention criteria
Citation

Arch Dis Child 61, 849-857

Nutr Neurosci 11, 61-68

Am J Clin Nutr 80, 903-910

J Dev Behav Pediatr 27, 371-378

J Pediatr 108, 681-689

Early Hum Dev 53, 251-269

$J$ Pediatr 143, 582-586

Biol Trace Elem Res 120 92-101

Acta Paediatr 96, 391-395

Eur J Clin Nutr 54, Suppl. 2, S114-S119

Asia Pac J Public Health 17, 19-21

Am J Clin Nutr 80, 729-736

$J$ Pediatr 100, 351-357

$J$ Dev Behav Pediatr 6, 69-75

Pediatrics 79, 981-995

Am J Clin Nutr 50, 3 Suppl., 641-651

N Engl J Med 5, 687-694

$J$ Pediatr 129, 382-389

Child Dev 69, 24-36

Pediatrics 105, E51

Pediatrics 112, 846-854

Arch Pediatr Adolesc Med

160, 1108-1813

J Nutr 137, 683-689

Eur J Clin Nutr 58,

1532-1542

J Nutr 137, 2756-2762

Clin Neurophysiol 115, 2259-2266

Lancet 9, 158

Am J Clin Nutr 43, 555-565

J Nutr 131, 2 Suppl. 2,

669S-675S

J Nutr 132, 2617-2625

Br J Nutr 48, 233-240

Hum Mov Sci 25, 821-838

Am J Clin Nutr 42 , 1221-1228

Am J Clin Nutr 50, 3 Suppl., 667-673

Pediatrics 120, 538-546

BMJ 15, 1389-1393

J Nutr 134, 2349-2354

J Pediatr 102, 519-522

Pediatrics 84, 7-17

Am J Clin Nutr 50, 3 Suppl., 655-661

Pediatr Int 42, 625-630

$J$ Pediatr Psychol 35, 296-305

Indian J Pediatr 77, 375-359

Pediatrics 126, e884-e894

NAID, non-anaemic iron deficiency. 
Table 2 Characteristics of studies included in the current review

\begin{tabular}{|c|c|c|c|c|c|c|c|c|c|}
\hline $\begin{array}{l}\text { Author, date, } \\
\text { country }\end{array}$ & Study design & Participants & Exclusion criteria & $\begin{array}{l}\text { Interventions, } \\
\text { dosage, duration }\end{array}$ & $\begin{array}{l}\text { Outcome } \\
\text { measures }\end{array}$ & $\begin{array}{l}\text { Side- } \\
\text { effects }\end{array}$ & $\begin{array}{l}\text { Adjusted } \\
\text { covariates }\end{array}$ & Drop-out & Findings \\
\hline $\begin{array}{l}\text { Akman et al., } \\
\text { 2004, Turkey }\end{array}$ & $\begin{array}{l}\text { Single-blind } \\
\text { RCT }\end{array}$ & $\begin{array}{l}\text { Children aged } \\
6-30 \text { months } \\
(108 \text { in total); } \\
\text { NAID }(n 40) ; \\
\text { treatment }(n 21) ; \\
\text { control }(n 19)\end{array}$ & $\begin{array}{l}\text { Pervasive } \\
\text { developmental } \\
\text { disorder or } \\
\text { severe mental } \\
\text { and motor } \\
\text { disability }\end{array}$ & $\begin{array}{l}\text { Oral ferrous- } \\
\text { glycine-sulfate } \\
\text { therapy }(3 \mathrm{mg} / \mathrm{kg} \\
\text { per d, twice } \\
\text { daily); } 3 \text { months }\end{array}$ & $\begin{array}{l}\text { BSID-I (MDI } \\
\text { and PDI) }\end{array}$ & NR & Unclear & $\begin{array}{l}\text { Among the total } \\
\text { participants the } \\
\text { parents of four } \\
\text { children declined } \\
\text { to participate and } \\
\text { two others } \\
\text { dropped out during } \\
\text { follow-up }\end{array}$ & $\begin{array}{l}\text { MDI score differences between } \\
\text { the NAID treatment and } \\
\text { control groups were found to } \\
\text { be significant after } 3 \text { months } \\
\text { of oral Fe treatment. Similar } \\
\text { findings were not found for } \\
\text { the PDI score }\end{array}$ \\
\hline $\begin{array}{l}\text { Idjradinata } \\
\text { et al., 1993, } \\
\text { Indonesia }\end{array}$ & $\begin{array}{l}\text { Double-blind } \\
\text { RCT }\end{array}$ & $\begin{array}{l}\text { Children aged } \\
12-18 \text { months } \\
(141 \text { in total); } \\
\text { NAID }(n \text { 29); } \\
\text { treatment }(n 14) ; \\
\text { control }(n 14)\end{array}$ & $\begin{array}{l}\mathrm{Hb} \text { between } 105 \\
\text { and } 120 \mathrm{~g} / \mathrm{l}\end{array}$ & $\begin{array}{l}\text { Oral ferrous sulfate } \\
\text { ( } 3 \mathrm{mg} / \mathrm{kg} \text { per } \mathrm{d}) \\
4 \text { months }\end{array}$ & $\begin{array}{l}\text { BSID (MDI } \\
\text { and PDI) }\end{array}$ & NR & $\begin{array}{l}\text { Mothers' } \\
\text { maximum } \\
\text { school grade }\end{array}$ & $\begin{array}{l}\text { Among the total } \\
\text { participants the } \\
\text { parents of fifteen } \\
\text { infants declined to } \\
\text { participate }\end{array}$ & $\begin{array}{l}\text { Pre-treatment to post-treatment } \\
\text { changes in the two } \\
\text { intervention subgroups within } \\
\text { the NAID group were not } \\
\text { significantly different }\end{array}$ \\
\hline
\end{tabular}

RCT, randomized controlled trial; NAID, non-anaemic iron deficiency; BSID, Bayley Scales of Infant Development; MDI, Mental Developmental Index; PDI, Psychomotor Developmental Index; NR, not reported.

Both the studies had the same inclusion criteria.

Table 3 Risk of bias table (quality assessment of included studies)

\begin{tabular}{|c|c|c|c|c|c|c|c|}
\hline $\begin{array}{l}\text { Author, date, } \\
\text { country }\end{array}$ & $\begin{array}{l}\text { Sequence } \\
\text { generation }\end{array}$ & $\begin{array}{l}\text { Allocation } \\
\text { concealment }\end{array}$ & $\begin{array}{l}\text { Blinding of participants, } \\
\text { personnel and outcome } \\
\text { assessors }\end{array}$ & $\begin{array}{l}\text { Incomplete } \\
\text { outcome data }\end{array}$ & $\begin{array}{l}\text { Selective outcome } \\
\text { reporting }\end{array}$ & Other bias & $\begin{array}{l}\text { ABC Cochrane } \\
\text { score }\end{array}$ \\
\hline $\begin{array}{l}\text { Akman et al., } \\
\text { 2004, Turkey }\end{array}$ & $\begin{array}{l}\text { Adequate (table of } \\
\text { random numbers) }\end{array}$ & $\begin{array}{l}\text { Unclear (no } \\
\text { information } \\
\text { was provided) }\end{array}$ & $\begin{array}{l}\text { Inadequate (a trained } \\
\text { psychologist, unaware } \\
\text { of each child's haemato- } \\
\text { logical status, administered } \\
\text { the BSID-I to all children } \\
\text { before and after the 3-month } \\
\text { follow-up; mothers were not } \\
\text { blinded due to placebo not } \\
\text { being used) }\end{array}$ & $\begin{array}{l}\text { Adequate (number and } \\
\text { reasons for drop-outs } \\
\text { and withdrawals were } \\
\text { described) }\end{array}$ & $\begin{array}{l}\text { Adequate (the IDA } \\
\text { group was the } \\
\text { main focus) }\end{array}$ & $\begin{array}{l}\text { Unclear } \\
\text { (adjustment } \\
\text { for other } \\
\text { biases) }\end{array}$ & $\begin{array}{l}\mathrm{B} \text { - moderate } \\
\text { risk of bias }\end{array}$ \\
\hline $\begin{array}{l}\text { Idjradinata et al., } \\
\text { 1993, Indonesia }\end{array}$ & $\begin{array}{l}\text { Adequate (table of } \\
\text { random numbers) }\end{array}$ & $\begin{array}{l}\text { Unclear (no } \\
\text { information } \\
\text { was provided) }\end{array}$ & $\begin{array}{l}\text { Adequate (placebo was a syrup } \\
\text { similar in appearance to the } \\
\text { ferrous sulfate } \\
\text { and both had a sweet, cherry } \\
\text { flavour) }\end{array}$ & $\begin{array}{l}\text { Adequate (number and } \\
\text { reasons for drop-outs } \\
\text { and withdrawals, the } \\
\text { procedure with } \\
\text { compliance were } \\
\text { described) }\end{array}$ & $\begin{array}{l}\text { Adequate (the IDA } \\
\text { group was the } \\
\text { main focus) }\end{array}$ & $\begin{array}{l}\text { Adequate } \\
\text { (adjustment } \\
\text { for other } \\
\text { biases) }\end{array}$ & $\begin{array}{c}B \text { - moderate } \\
\text { risk of bias }\end{array}$ \\
\hline
\end{tabular}

BSID, Bayley Scales of Infant Development; IDA, iron-deficiency anaemia. 


\begin{tabular}{|c|c|c|c|c|c|c|c|c|c|c|}
\hline \multirow[b]{2}{*}{ Study or subgroup } & \multicolumn{3}{|c|}{ Experimental } & \multicolumn{3}{|c|}{ Control } & \multirow{2}{*}{$\begin{array}{c}\text { Mean difference } \\
\text { IV, random }(95 \% \mathrm{Cl})\end{array}$} & \multirow{2}{*}{\multicolumn{2}{|c|}{$\begin{array}{c}\text { Mean difference } \\
\text { IV, random }(95 \% \mathrm{Cl})\end{array}$}} & \\
\hline & Mean & SD & Total & Mean & SD & Total & & & & \\
\hline Akman et al., 2004 & $101 \cdot 52$ & 8.76 & 21 & $95 \cdot 26$ & $6 \cdot 4$ & 19 & $6 \cdot 26(1.54,10 \cdot 98)$ & & -1 & \\
\hline Idjradinata et al., 1993 & $107 \cdot 7$ & $10 \cdot 5$ & 14 & $109 \cdot 3$ & $10 \cdot 5$ & 14 & $-1 \cdot 60(-9 \cdot 38,6 \cdot 18)$ & & & \\
\hline & & & & & & & -2 & -10 & 10 & 20 \\
\hline
\end{tabular}

Fig. 2 Forest plot of comparison: developmental scores (outcome is Mental Developmental Index, MDI) of non-anaemic iron-deficient pre-school children on iron supplementation $v$. no treatment/placebo; mean differences with $95 \%$ confidence intervals represented by vertical lines (IV, inverse variance). Study results are not combined

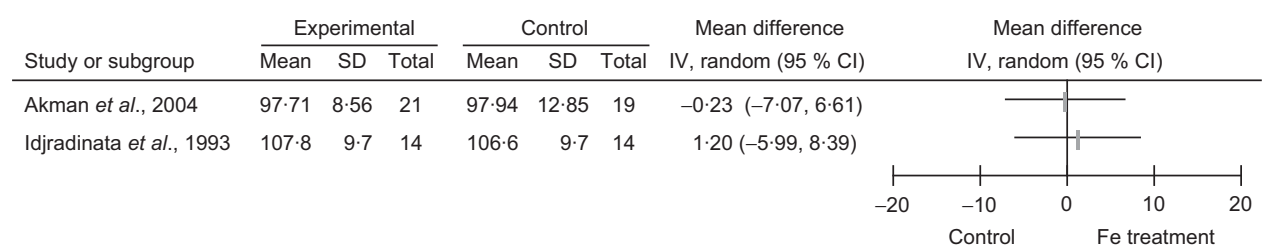

Fig. 3 Forest plot of comparison: developmental scores (outcome is Psychomotor Developmental Index, PDI) of non-anaemic iron-deficient pre-school children on iron supplementation $v$. no treatment/placebo; mean differences with $95 \%$ confidence intervals represented by vertical lines (IV, inverse variance). Study results are not combined

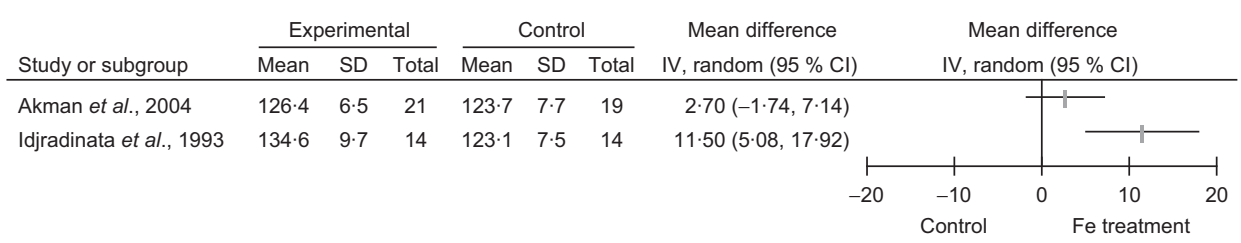

Fig. 4 Forest plot of comparison: haematological outcome $(\mathrm{Hb}, \mathrm{g} / \mathrm{l})$ of non-anaemic iron-deficient pre-school children on iron supplementation $v$. no treatment/placebo; mean differences with $95 \%$ confidence intervals represented by vertical lines (IV, inverse variance). Study results are not combined

\begin{tabular}{|c|c|c|c|c|c|c|c|c|c|c|}
\hline \multirow[b]{2}{*}{ Study or subgroup } & \multicolumn{3}{|c|}{ Experimental } & \multicolumn{3}{|c|}{ Control } & \multirow{2}{*}{$\begin{array}{c}\text { Mean difference } \\
\text { IV, random }(95 \% \mathrm{Cl})\end{array}$} & \multirow{2}{*}{\multicolumn{2}{|c|}{$\begin{array}{c}\text { Mean difference } \\
\text { IV, random }(95 \% \mathrm{Cl})\end{array}$}} & \\
\hline & Mean & SD & Total & Mean & SD & Total & & & & \\
\hline Akman et al., 2004 & 33.49 & $20 \cdot 05$ & 21 & $16 \cdot 43$ & $9 \cdot 36$ & 19 & $17 \cdot 06(7 \cdot 51,26 \cdot 61)$ & & -1 & \\
\hline Idjradinata et al.,1993 & $63 \cdot 1$ & $32 \cdot 6$ & 14 & $12 \cdot 0$ & $7 \cdot 1$ & 14 & $51 \cdot 10(33 \cdot 62,68 \cdot 58)$ & & - & \\
\hline & & & & & & & -100 & -50 & 50 & 100 \\
\hline
\end{tabular}

Fig. 5 Forest plot of comparison: haematological outcome (serum ferritin, $\mu \mathrm{g} / \mathrm{l}$ ) of non-anaemic iron-deficient pre-school children on iron supplementation $v$. no treatment/placebo, outcome; mean differences with $95 \%$ confidence intervals represented by vertical lines (IV, inverse variance). Study results are not combined

the post-treatment MDI score $(\mathrm{MD}=6 \cdot 3,95 \%$ CI $1 \cdot 5$, $11 \cdot 0, P$ value not provided); and comparison of the posttreatment PDI score showed no statistically significant difference $(\mathrm{MD}=-0 \cdot 2,95 \% \mathrm{CI}-7 \cdot 0,6 \cdot 6$; Figs 2 and 3 ). Idjradinata et al. (1993, Indonesia) showed no statistically significant difference in either the post-treatment MDI score $(\mathrm{MD}=-1 \cdot 6,95 \% \mathrm{CI}-9 \cdot 4,6 \cdot 2)$ or the post-treatment PDI score $(\mathrm{MD}=1 \cdot 2,95 \% \mathrm{CI}-6 \cdot 0,8 \cdot 4$; Figs 2 and 3$)$.

Considering the secondary outcomes, namely the comparison of $\mathrm{Hb}$ and serum ferritin levels in the Fe-treated and non-treated NAID groups, Idjradinata et al. (1993, Indonesia) reported a statistically significant increase in the post-treatment $\mathrm{Hb}$ level $(\mathrm{g} / \mathrm{l}: \mathrm{MD}=11 \cdot 5$,
95\% CI 5•1, 17·9, $P<0 \cdot 01)$ and the post-treatment serum ferritin level $(\mu \mathrm{g} / \mathrm{l}: \mathrm{MD}=51 \cdot 1,95 \%$ CI 33·6, 68・6, $P<0 \cdot 01$; Figs 4 and 5). Akman et al. (2004, Turkey) reported no statistically significant increase in post-treatment $\mathrm{Hb}$ level $(\mathrm{g} / \mathrm{l}: \mathrm{MD}=2 \cdot 7,95 \% \mathrm{CI}-1 \cdot 7,7 \cdot 1)$; but the ferritin level showed a significant increase $(\mu \mathrm{g} / \mathrm{l}: \mathrm{MD}=17 \cdot 1,95 \% \mathrm{CI} 7 \cdot 5$, 26.6, $P$ value not provided; Figs 4 and 5 ). Neither of the studies intended to report side-effects.

\section{Heterogeneity and publication bias}

Clinical heterogeneity between the studies is described in Table 2. Some of this heterogeneity can be explained by the difference in the range of age of the children in the 
two studies. The children in Akman et al. were relatively older compared with Idjradinata et al. (mean age, months: $18(\mathrm{SD} 6 \cdot 1) v .14(\mathrm{SD} 0 \cdot 51))$. Other potential causes of heterogeneity include the exclusion criteria and duration of Fe treatment ( 3 months $v$. 4 months). The drop-out rates for the two studies were approximately $6 \%$ and $11 \%$ (of the total participants). Neither study reported the characteristics of the children who declined to participate. Only Idjradinata et al. reported the results after adjusting for mothers' maximum school grade and no clear information regarding adjustment for covariates was reported in Akman et al.'s study. When we attempted to combine the results of the two studies, evidence of high statistical heterogeneity was observed. The combined result for the MDI score showed a $Q$ value of $3.51(P=0 \cdot 06)$ and an $I^{2}$ value of $72 \%$, indicating significant statistical heterogeneity. For the PDI score the $Q$ value was $0 \cdot 08(P=0 \cdot 8)$ and the $I^{2}$ value $0 \%$, indicating less heterogeneity. However we were not able to estimate the between-study variance with precision with only two studies because the $\pi^{2}$ (variability) as well as $I^{2}$ become 0 when $Q \leq k-1$ $(\mathrm{df}=1)$. Due to the lack of homogeneity between the studies we decided not to show the combined effect size of the results. We are unable to comment on the publication bias issue with only two included studies.

\section{Subgroup and sensitivity analyses}

Since only two studies met the inclusion criteria, this restricted us from performing any predefined subgroup or sensitivity analyses.

\section{Discussion}

\section{Major findings}

In the current systematic review, two randomized controlled trials were identified for children of pre-school age with NAID treated with oral Fe treatment $v$. no treatment. This limited number of identified studies on NAID shows the need to carry out more research on this very important topic. Furthermore, due to high level of clinical, methodological and statistical heterogeneity we were unable to combine the results of the trials. One study demonstrated a significant difference in the BSID MDI post oral Fe treatment ${ }^{(28)}$. Neither study demonstrated a significant difference in the post-treatment BSID PDI. However, neither study adjusted for pre-treatment development score. Therefore, the efficacy of oral Fe therapy in children with NAID to improve developmental outcome remains in question.

For the haematological outcomes, both studies demonstrated a significant improvement in the post-treatment serum ferritin levels. One demonstrated a significant improvement in the post-treatment $\mathrm{Hb}_{\text {level }}{ }^{(27)}$. The other study, despite demonstrating a significant improvement in post-treatment serum ferritin level, did not demonstrate a significant difference in post-treatment $\mathrm{Hb}$ level ${ }^{(28)}$. A possible explanation for this finding is that these children may have had very mild ID. It has been shown in therapeutic trials of $\mathrm{Fe}$ treatment that children with greater ID respond to $\mathrm{Fe}$ treatment at a higher rate (increase of $\mathrm{Hb} 10 \mathrm{~g} / \mathrm{l}$ is indicative of ID) ${ }^{(29)}$.

\section{Limitations}

Several methodological and statistical issues lead to the finding that both studies had moderate risk of bias. These issues include: no information regarding allocation concealment (both studies), inadequate blinding of participants (Akman et al.), no clear statement of adjustment for biases (Akman et al.) and no clear statement on adjustment for various confounders. Another important limitation to these studies was the lack of power to demonstrate a difference in children with NAID. Idjradinata et al. stated: 'If the developmental effects of non-anemic iron deficiency were smaller than those of iron-deficiency anemia then the sample size needed to detect such differences would have to be larger than the sample included in the present study $^{(27)}$. In addition, a comprehensive review on the effect of ID on the development of children by GranthamMcGregor and Ani (2001) specifically emphasized the importance of power and sample size ${ }^{(5)}$.

\section{Relation of findings to those of similar studies}

A recently published review of prophylactic administration of Fe to healthy infants and pregnant mothers showed no improvement in $\mathrm{MDI}^{(30)}$. Meta-analysis of three of the five included studies revealed a 4-point increase in PDI; however, the numbers of infants and studies included in the review were too small to make any conclusive recommendation for screening for ID in young children. The current review is fundamentally different from the above-mentioned one where the effect of prophylactic administration of Fe to non-ID children was examined. We focused our review on healthy children with NAID.

To date, most of the attention regarding ID has been focused on the impact of Fe treatment in children with IDA $^{(5,6)}$. Studies focusing on Fe treatment for children with IDA are unable to provide relevant data for children with NAID. The reasons for this gap in knowledge include study groups not being categorized according to the different levels of ID; no control group for the subsets of ID; most studies compared IDA with Fe-sufficient children or children with lower level of ID. This underscores the importance of studies specifically aimed at children with NAID, which is a highly prevalent and under-recognized condition in young children both in developing and developed nations.

\section{Implication on practice}

Evidence is insufficient to recommend Fe treatment to children with NAID. 


\section{Implication on research}

There is an urgent need for research examining the effectiveness of oral Fe treatment in children of pre-school age with NAID in respect to their developmental outcome. In order to determine if NAID is causally associated with poor development and to determine the efficacy of oral Fe treatment, adequately powered (to identify a significant difference between Fe-treated and not treated groups of children with NAID) and well-designed blinded, randomized controlled trials must be conducted. In addition, reporting of side-effects of Fe treatment should be emphasized in these trials.

\section{Conclusions}

Our findings suggest that data regarding developmental outcomes of children with NAID following treatment with oral Fe abstracted from trials specifically aimed at understanding the relationship between Fe and development in children with IDA are few and inconclusive. NAID as a cause of poor development and the efficacy of oral Fe therapy to reverse or prevent Fe-related developmental impact in this population can only be achieved by randomized trials specifically targeting children with NAID. It is imperative that these trials have adequate sample size to detect significant differences in the NAID population. Current evidence indicating the irreversible nature of IDA further strengthens the need to identify and treat children with ID while they are still in the non-anaemic stage.

\section{Acknowledgements}

Sources of funding: The Pediatric Outcomes Research Team is supported by a grant from the Hospital for Sick Children Foundation. K.A. was supported by the Ontario Graduate Scholarship (OGS, 2009) and the Canadian Institute of Health Research Masters' Award (CIHR, 2010). Conflicts of interest: None of the authors have any conflict of interest to declare. Authors' contributions: K.A., P.S. and P.C.P. contributed to the analysis and interpretation of data, drafting of the manuscript and critical revision of the manuscript for important intellectual content. T.K. and E.U. contributed to the search and review of articles for consideration of inclusion in the systematic review and critical revision of the manuscript. K.A. has full access to all data in the study and takes responsibility for the integrity of the data and the accuracy of the data analysis.

\section{References}

1. Tulchinsky TH \& Vatavikova EA (2009) The New Public Health, 2nd ed. Burlington, MA: Elsevier Academic Press.

2. World Health Organization/UNICEF/United Nations University (2001) Iron Deficiency Anaemia: Assessment, Prevention, and Control. A Guide for Programme Managers (WHO/NHD/ 01.3). Geneva: WHO.
3. Yager JY \& Hartfield DS (2002) Neurologic manifestations of iron deficiency in childhood. Pediatr Neurol 27, 85-92.

4. Lozoff B, Beard J, Connor J et al. (2006) Long-lasting neural and behavioral effects of iron deficiency in infancy. Nutr Rev 64, 5 Pt 2, S34-S43.

5. Grantham-McGregor S \& Ani C (2001) A review of studies on the effect of iron deficiency on cognitive development in children. J Nutr 131, 2 Suppl. 2, 649S-668S.

6. Logan S, Martins S \& Gilbert RE (2001) Iron therapy for improving psychomotor development andcognitive function in children under the age of three with iron deficiency anaemia. Cochrane Database Syst Rev issue 2, CD001444.

7. Lozoff B, Brittenham GM, Wolf AW et al. (1987) Iron deficiency anemia and iron therapy effects on infant developmental test performance. Pediatrics 79, 981-995.

8. Pollitt E, Saco-Pollitt C, Leibel RL et al. (1986) Iron deficiency and behavioral development in infants and preschool children. Am J Clin Nutr 43, 555-565.

9. Soewondo S, Husaini M \& Pollitt E (1989) Effects of iron deficiency on attention and learning processes in preschool children: Bandung, Indonesia. Am J Clin Nutr 50, 3 Suppl., 667-674.

10. Scrimshaw N (1990) Functional significance of iron deficiency: an overview. In Annual Nutrition Workshop Series. vol III: Functional Significance of Iron Deficiency, pp. 1-13 [CO Enwonwu, editor]. Nashville, TN: Meharry Medical College.

11. Otero GA, Aguirre DM, Porcayo R et al. (1999) Psychological and electroencephalographic study in school children with iron deficiency. Int J Neurosci 99, 113-121.

12. Baker RD \& Greer FR (2010) Diagnosis and prevention of iron deficiency and iron-deficiency anemia in infants and young children (0-3 years of age). Pediatrics 126, 1040-1050.

13. Owen GM, Lubin AH \& Garry PJ (1971) Preschool children in the United States: who has iron deficiency? J Pediatr 79, 563-568.

14. de Andraca I, Walter T, Castillo M et al. (1990) Iron deficiency anemia and its effects upon psychological development at preschool age: a longitudinal study. In Nestlé Foundation Annual Report, 1990, pp. 53-62. Lausanne: Nestlé Foundation.

15. Lozoff B, Jimenez E \& Wolf AW (1991) Long-term developmental outcome of infants with iron deficiency. $N$ Engl J Med 325, 687-694.

16. Ramdath DD, Simeon DT, Wong MS et al. (1995) Iron status of schoolchildren with varying intensities of Trichuris trichiura infection. Parasitology 110, 347-351.

17. Lane PA, Nuss R \& Ambruso DR (2001) Hematologic disorder. In Current Pediatric Diagnosis \& Treatment, 15th ed., vol. 26, pp. 748-749. [WW Hay, AR Hayward, MJ Levin et al., editors]. Beijing: People's Medical Publishing House.

18. Mora J (2002) Iron supplementation: overcoming technical and practical barriers. J Nutr 132, 4 Suppl., 853S-855S.

19. Bridges KR \& Person HA (2003) Iron deficiency. In Rudolph's Pediatrics, 21st ed., vol. 19.3.1, section 23, part 2, pp. 431-432 [CD Rudolph and AM Rudolph editors]. Beijing: People's Medical Publishing House.

20. Fairbanks VF \& Beutler E (2001) Iron deficiency. In Williams Hematology, 16th ed., vol. 38, pp. 447-470 [E Beutler, MA Lichtman, BS Coller et al., editors]. Beijing: People's Medical Publication House.

21. Galloway R \& McGuire J (1994) Determinants of compliance with iron supplementation: supplies, side effects or psychology? Soc Sci Med 39, 381-390.

22. Sheard N (1994) Iron deficiency and infant development. Nutr Rev 52, 137-146.

23. Stoltzfus R (2001) Defining iron-deficiency anemia in public health terms: a time for reflection. $J$ Nutr 131, 2 Suppl. 2, 565S-567S.

24. Lichtenberger E (2005) General measure of cognition for the pre-school child. Ment Retard Dev Disabil Res Rev 11, 197-208. 
25. Higgins JPT \& Green S (editors) (2011) Cochrane Handbook for Systematic Reviews of Interventions, Version 5.1.0. The Cochrane Collaboration. http://www.cochrane-handbook.org (accessed August 2012)

26. Wells GA, Shea B, O'Connell D et al. (2000) The NewcastleOttawa Scale (NOS) for assessing the quality of nonrandomised studies in meta-analyses. http://www.ohri.ca/programs/ clinical_epidemiology/oxford.asp (accessed August 2012).

27. Idjradinata P \& Pollitt E (1993) Reversal of developmental delays in iron deficient anaemic infants treated with iron. Lancet 341, 1-4.

\section{Appendix}

\section{Search strategy for MEDLINE}

1. anemia, hypochromic/or anemia, iron-deficiency/or Iron/bl or exp Ferritins/bl

2. exp Psychomotor Performance/or exp psychiatric status rating scales/or exp psychological tests/or exp child development/or mental competency/or (Bayley* adj5 scale*).ti,ab. or child behavior disorders/or exp communication disorders/or developmental disabilities/ or exp learning disorders/or mental retardation/or motor skills disorders/or exp Cognition/
28. Akman M, Cebeci D, Okur V et al. (2004) The effects of iron deficiency on infants' developmental test performance. Acta Paediatr 93, 1391-1396.

29. Kazal L (2002) Prevention of iron deficiency in infants and toddlers. Am Fam Physician 66, 1217-1224.

30. Szajewska H, Ruszczynski M \& Chmielewska A (2010) Effects of iron supplementation in nonanemic pregnant women, infants, and young children on the mental performance and psychomotor development of children: a systematic review of randomized controlled trials. Am J Clin Nutr 91, 1684-1690.

3. (randomized controlled trial or controlled clinical trial).pt. or randomized controlled trials/or random allocation/ or double-blind method/or single-blind method/or clinical trial.pt or exp clinical trials/or placebos/or research design/or (clinic\$ adj25 trial\$).mp or ((singl\$ or doubl\$ or trebl\$ or tripl\$) adj (mask\$ or blind\$)).mp. or (placebo\$ or random\$).mp. or (latin adj square).mp. or comparative study/or exp evaluation studies/or follow-up studies/or prospective studies/or cross-over studies/or (control\$ or prospective\$ or volunteer\$).mp. or retrospective studies/ or cohort studies/or cross-sectional studies/

4. 1 and 2 and 3 